\title{
An Action Design Research on Development and Deployment of a Computer- Based Group Discussion Support Tool for Achieving Consensus and Culture Change at an Educational Institution
}

\author{
J. Lee ${ }^{1}$, J. V. Hillegersberg ${ }^{2}$, K. Kumar ${ }^{3}$ \\ ${ }^{1}$ Human Resources Department, Singapore University of Technology and Design, Singapore, \\ ${ }^{2}$ Department of Industrial Engineering and Business Information Systems, University of Twente, Enschede, Netherlands \\ ${ }^{3}$ Department of Industrial Engineering and Business Information Systems, University of Twente, Enschede, Netherlands \\ (jaclynlee@sutd.edu.sg ${ }^{1}$ )
}

\begin{abstract}
Organisational culture change is a long and complex process that typically takes years to complete and has a very low success rate. This project addresses the problem by the proposed use of an Action Design Research Methodology to build and deploy an IT artifact named Organisational Culture Assessment Instrument-Spilter (OCAI-Spilter) to speed up cultural change while reducing failure rate. OCAI-Spilter should be able to fast-track culture change by addressing the problem of scalability and process losses encountered in most change projects involving large numbers of people. We used an iterative prototyping process to continuously refine the tool in use. We also reviewed the design principles in Action Research Design to improve the usability of the tool. New design principles and learning were derived from this process. Finally, we showed the effectiveness of the artifact by measuring the results of the tool in use through culture surveys and alignment, as well as idea generation that was administered through the tool.
\end{abstract}

Keywords - Organisational culture change, Organisational Culture Assessment Instrument, action design research

\section{INTRODUCTION}

Culture change is a long and complex process that can take years to complete. Most current manual methods for culture change are long and tedious and their success rates typically low. [1]reported that only $10-32 \%$ of companies in transformation attain the desired cultural shift. [2] stated that cultural change "is not easy to achieve; it is a difficult, complicated, demanding effort that can take several years to accomplish."

In this case study of a tertiary educational institution, we demonstrated how, through the use of an IT artifact, we were able to reduce the long process time it took to manage culture alignment and change. This educational institution currently has a vision is to introduce disruptive change and innovation as an alternative to the traditional engineering education that is typically offered. As a result of this innovative vision, the institution is offering nontraditional engineering degrees with a multi-disciplinary focus. Organisational culture becomes important as we need the right culture to foster the type of innovation that is required for it to be successful.

However, various stakeholders in an organisation often have different motivations, agendas, background and perceptions of current and desired states of culture. In addition, other issues such as attitudes that "reinforce traditional professional hierarchies and stereotypes" [3]issues of unequal workload [4], conflicts between team and individual professional goals [5], role ambiguity [6], and mismatched expectations [7] also affect how stakeholders may perceive the current and desired cultures differently.

We thus need to measure current and desired culture states to understand the gap and obtain alignment between various stakeholders. Next, we need to engage in group discussions to develop ideas for change management initiatives to close these gaps.

This research focused on creating a scalable tool for measuring culture. If we are able to develop a tool that could readily assess culture and changes in culture, we could continuously and regularly assess if the culture change process is moving in the desired direction. Given the relatively large number of senior management, faculty, staff and students in the institution, we require an organisational culture change process and an organisational culture tool that can be scaled up to measure, assess and change the culture of large groups of stakeholders in an effective and timely manner.

\section{A. Research aims}

a. Measure and make explicit the perceived current and desired cultures of each stakeholder group.

b. To allow a platform for all stakeholder groups such senior management, faculty, administrative staff, and students, to be able reach an intergroup agreement or a consensus understanding of the current and desired cultures

c. Based upon this inter-group consensus to identify the differences or gaps between the consensus current and desired cultures for each group.

d. To collectively discuss and come to an agreement about the possible means of reducing these gaps between current and desired cultures 


\section{B. Uses of the tool}

a. Collecting, grouping, summarizing, graphing, and reporting culture survey data from multiple participants;

b. Supporting group discussion and decisionmaking at both intra and inter group levels for arriving at a consensus and agreed culturechange measures

The effectiveness of this tool can only be assessed and iteratively developed by the "tool-in-use." Therefore while our research objective was the development of a computer-assisted measurement, representation, and group discussion support tool, it was important to evaluate the usefulness of this tool, and gradually improve it in real live "use conditions". In the development of this tool we followed a prototyping process and employed the use of group decision support systems (GDSS) in the development. Research has repeatedly pointed out [8]that GDSS technology has tremendous potential for improving group performance. Based upon this previous research, our assertion is that the GDSS technology can be used for culture change and consensus building. Moreover, the GDSS technology can support the purported culture tool by increasing its scalability and ameliorate its current shortcomings of process losses..

We followed an action design research (ADR) methodology for the research project. The ADR methodology integrates the development of an artifact (Design Research), and the use of this artifact for organisational action (Action Research). It deals with two seemingly disparate challenges:

1. Addressing a problem situation encountered in a specific organizational setting by intervening and evaluating; and

2. Constructing and evaluating an IT artifact that addresses the class of problems typified by the encountered situation[9].

\section{LITERATURE REVIEW}

Our literature review focused on four key topics, organisation culture and organisational culture assessment instrument(OCAI), group decision support systems, action design research and prototyping. The literature review will be used to gather the requirements for the development of the tool.

\section{A. Organization Culture and OCAI}

[10]defines organizational culture as, "the taken-forgranted values, underlying assumptions, expectations, and definitions that characterize organizations and their members. It is an enduring slow-to-change core characteristic of organisations". [10,11]define culture as "shared" perceptions of organisational work practices within organisational units. Given that these are shared perceptions; it is important that members of the organisation participate in the process of agreeing upon their perceptions of the current culture; and desired cultures, and share their perceptions. To begin the process of culture change, it is important to understand the collective thought processes of the organisation by measuring the current culture of an organisation and comparing it to the desired organisational culture. This is followed by an assessment of the culture gap, and subsequent change programs to close the gap between current and desired culture.

The chosen culture tool in this research is the organisational culture assessment instrument (OCAI). It has strong face validity, is easy to use and administer, especially when integrated into our designed artefact.[4] also shows that the OCAI has a strong theoretical basis, and as explained, accesses both congruence and strength of culture. In addition, to this, the adhocracy and the clan quadrants of the culture instrument reflect and integrate well with the innovation and multi-disciplinary culture of the educational institution. The OCAI employs the competing values framework(CVF)[10]. CVF/OCAI classifies organisations into four quadrants: clan, hierarchy, market, and adhocracy. It does so, based upon allocating 100 points among these four quadrants for sixdimensions or six facets of the organization[10].

\section{B. Group Decision Support Systems (GDSS) -}

[12] was one of the first authors who expounded the need for the use of GDSS systems. He noticed in the early days that, "the need for such group decision support systems, whether designed by the user or by a vendor, is a consequence of the clash of two important forces - the environmentally-imposed demand for more information sharing in organizations and the resistance to still more meetings. Later, [13]observed that electronic meeting systems in the early days were used to directly impact and change the behaviour of groups to improve group effectiveness, efficiency, and satisfaction. This technology results in less process losses, and speeds up group decision making.

\section{Action Design Research (ADR) Methodology}

In [14], the authors observed that information system (IS) as a discipline has been accused of having no relevance in the practical world. Research needs to make a dual contribution to academia and practice. Two research methods with this dual orientation is design research (DR) and action research (AR). As shown by[15], both these methodologies though distinct, are closely related and offer unique strengths to the research community. By examining two distinct projects with overlapping AR and DR, they found that the two methods shared important assumptions regarding ontology, epistemology, and axiology. The authors proposed a 
model to integrate the two approaches together. Their integrated model involves four ADR steps which will be explained in more detail in the methodology section.

\section{Prototyping as a systems/software development process}

GDSS and DSS are typically developed using a prototyping process; moreover, the requirements for the GDSS, and the GDSS itself, are continually and iteratively improved using this prototyping process. Therefore it is important to review and learn from the extant state of knowledge about prototyping systems and its development processes. Key theories expounded here are from [16]thirteen-step process for GDSS development and [17]four prototyping strategies: horizontal, vertical, task oriented and scenario based prototypes.

\section{RESEARCH METHDOLOGY}

Since we are developing an "artifact-in-use" by organizational actors, we used an Action Design Research Methodology[9] Following the suggestion by [9] the design of the artifact was informed by both functional and technical requirements for the artifact, derived from the literature review, as well as "shaped by the interests, values, and assumptions of a wide variety of communities of developers, investors, users" [18]without letting go of the essence of design research(DR) which is:

(1) innovation and

(2) dealing with a class of problems and systems." [9]

\section{A. ADR Methodology}

We also followed the four-stage ADR methodology described in [9]. There are four steps to this methodology:

1. Problem formulation

2. Building, intervention and evaluation (BIE) It is either IT dominant or organisation dominant

3. Reflection and learning

4. Formalization of learning

In this research we used an Organization Dominant BIE. The OCAI-Spilter artifact was deployed in the design iterations and tested with members of the university. Feedback obtained was incorporated into subsequent versions of the artifact till changes and improvements became stable and only marginal changes were observed in iterations. Throughout the process, we kept a record of observations of the artifact "in-use," and the consequent, iterative, continuous, improvements to our artifact. The culture instrument in use is the OCAI culture measurement instrument. For the GDSS system we used Spilter, a commercial - web-based GDSS developed in The Netherlands and available free for research, at the University of Twente, department of Industrial Engineering and Information Systems. The IT artifact so produced is called the OCAI-Spilter system. We used Spilter as our GDSS for the following reasons -

1. It is available free of charge for research purposes

2. It is relatively easy to integrate Spilter with the OCAI questionnaire

3. The system uses web technology and can be used on ubiquitous devices such as iPAD and on most browsers.

4. As a group discussion tool, the system is relatively easy to use, and can most immediately generate live results of discussions and voting for quick decision making

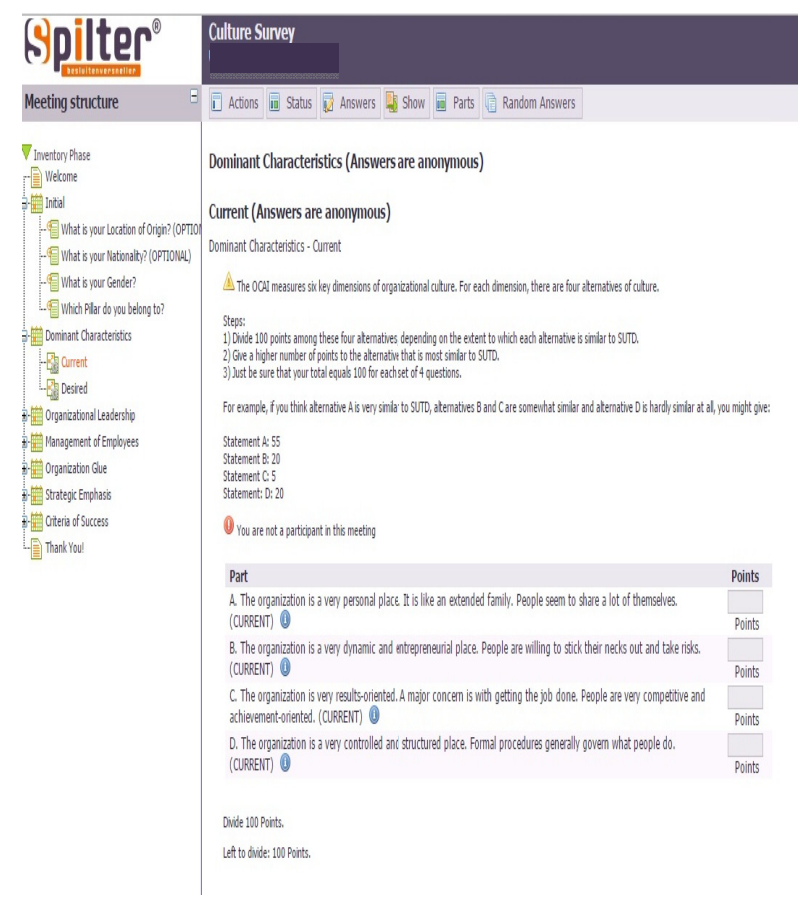

Fig. 1. Sample Spilter Screen for Culture Survey

The design principles of the OCAI-Spilter artifact included:-

1. Automating the OCAI culture survey within the Spilter system to allow for easy participation and understanding of the current and desired culture states of the institution as can be seen in Figure 1 .

2. Creating a platform in Spilter for discussion on the results of the culture survey, obtaining alignment on desired culture and generating ideas to close the gap. This can be seen in Figure 3. 


\section{Design Iterations}

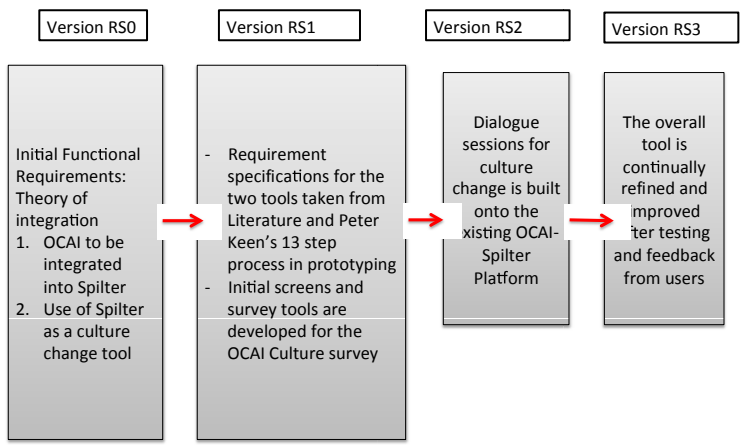

Fig. 2. Design Iterations of the OCAI-Spilter

\section{B. Design Iterations and Functional Requirements}

The design process in the development of the OCAISpilter included the following steps.

1. Developing functional requirements

2. Building usable screens for the prototype

3. Building iterations with organisational intervention in the prototype

4. Finalising the prototype after the feedback and iterations

5. Reflection and learning principles

The tool was deployed to staff, faculty and students alike to participate in the OCAI culture survey. After the culture surveys were collected and results tallied, we used the GDSS function in Spilter to conduct group discussions on culture change and the subsequent gap analysis. The results obtained were compared to previous manual methods of conducting the same survey and culture change discussion.

\section{RESULTS}

A. Improvement in participation rates using the OCAISpilter versus manual method. Only staff and faculty results are available for comparison in this table as students did not participate in the manual versions. See (Table 1):

B. Robust data set from a high participation rate allowed for improved generation of organisational wide culture results (Table 2):

C. Enhanced ability to generate ideas on change within a shorter period of time

(Table 3):

TABLE 1:

\begin{tabular}{rcc}
\hline & \multicolumn{2}{c}{ OCAI culture survey participation rate } \\
\cline { 2 - 3 } & Staff & Faculty \\
\hline $\begin{array}{r}\text { Manual } \\
\text { method }\end{array}$ & $25 \%$ & $15 \%$ \\
OCAI-Spilter & $66 \%$ & $45 \%$ \\
\hline
\end{tabular}

TABLE 2:

Generation of organisational wide results and desired culture states

\begin{tabular}{rll}
\hline & \multicolumn{2}{c}{ Generation of organisation wide results } \\
\cline { 2 - 3 } Clan & 23.61 & Desired mean \\
\hline Adhocracy & 22.64 & 32.92 \\
Market & 25.81 & 29.87 \\
Hierarchy & 27.85 & 18.92 \\
& & 18.92 \\
Dominant & Hierarchy Market & \\
$2{ }^{10}$ Highest & & Clan Adhocracy \\
Lowest & Clan & Hierarchy \\
Main & Stability and Control & Flexibility and \\
Dimensions & & Discretion \\
\hline
\end{tabular}

TABLE 3

Improvements in results of culture alignment discussions

\begin{tabular}{rlc}
\hline & \multicolumn{2}{c}{ Cultural alignment discussion } \\
\cline { 2 - 3 } & Time Taken & Ideas Generated \\
\hline $\begin{array}{r}\text { Manual } \\
\text { method }\end{array}$ & 5 hours & 5 Key Ideas \\
OCAI-Spilter & 1 hour & 10 Key Ideas \\
\hline
\end{tabular}

Wilcome screen.

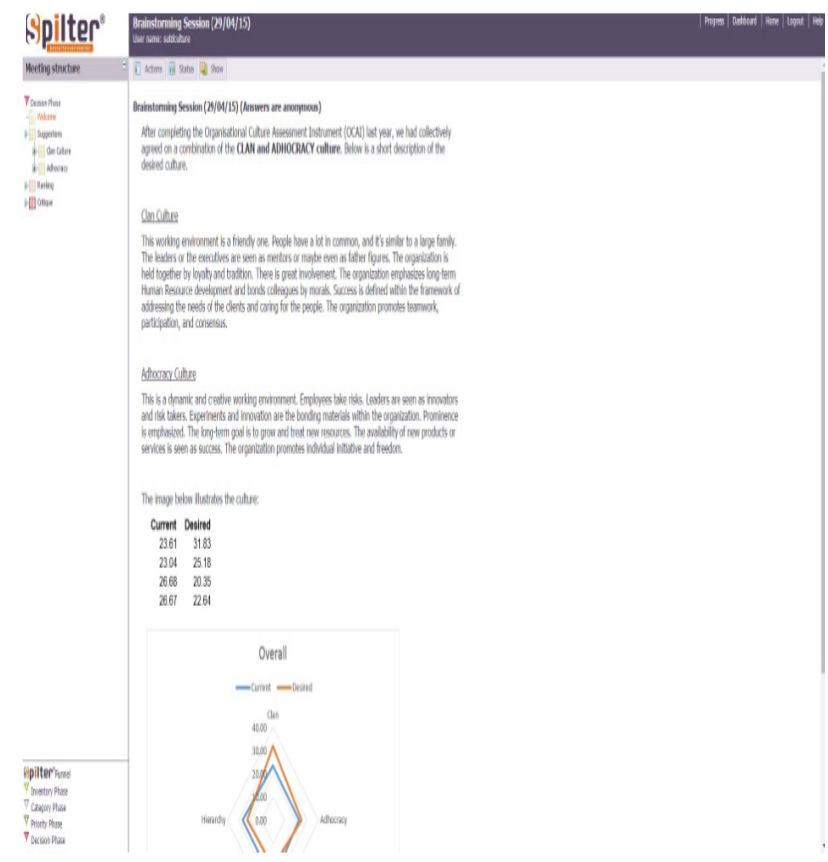

Fig. 3. Sample Screen of Spilter for Culture Discussion 


\section{CONCLUSION}

The study has shown that the OCAI-Spilter instrument was able to increase participation rates of the culture survey, obtained alignment between different stakeholders, and improved idea generation within a shorter period of time. Process losses typically encountered in large group sessions were significantly reduced.

Many organisations today grapple with how to align their employees with the organisation's objectives and vision. If this alignment can be quickly achieved through a tool that can speed up culture change and improve idea generation to close culture gaps, this would greatly facilitate the success of any change effort. [19]states that broad based meaningful engagement and participation across business units, functions and levels is a key mechanism for mobilizing and building ownership and engagement. Increased ownership and engagement ultimately leads to success.

\section{LIMITATION OF STUDY}

Change is very complex and every organisation faces different challenges depending on its business objectives, goals, background and training of its employees. While the tool can facilitate change efforts, and help improve as well as speed up the process of culture change, leadership and effective facilitation remain a key role in determining whether such change efforts within organisations can be successful in the long run.

\section{REFERENCES}

[1] M. E. Smith, "Changing an organisation's culture: Correlates of success and failure," Leadership \& Organization Development Journal, vol. 24, no. 5, pp. 249261, 2003.

[2] K A Baker. (2002) [Online]. http://www.au.af.mil/au/awc/awcgate/doe/benchmark/ch11. pdf

[3] Wilson V and Pirrie A, "Multidisciplinary Teamworking. Beyond the Barriers?," Scottish Council for Research in Education., 77, 2000

[4] John Ovretveit, "Social identity theory: past achievements, current problems and future challenges: Interprofessional working for health and social care," 1997.

[5] Steve Onyett, Tracey Pillinger, and Matt MUIJEN, "Job satisfaction and burnout among members of community mental health teams," Journal of Mental Health, vol. 6, no. 1, pp. 55-66, 1997.

[6] V Jenkins, L Fallowfield, and Saul J, "Information needs of patients with cancer: results from a large study in UK cancer centres," Br J Cancer, vol. 1, no. 84, pp. 48-51, Jan 2001

[7] P Bosch-Sijtsema, "The impact of individual expectations and expectation conflicts on virtual teams," Group \& organization management, vol. 3 , no. 32, pp. 368 - 388, 2007.
[8] J. S Valacich, A. R Dennis, and T. Connolly, "Idea generation in computer-based groups: A new ending to an to an old story," Organizational behavior and human decision processes, vol. 57, no. 3, pp. 448-467, 1994.

[9] M K Sein, Ola Henfridsson, Purao Sandeep, Matti Rossi, and Rikard Lindgren, "Action Design Research," MIS Quarterly, vol. 35, no. 1, pp. 37-55, March 2011.

[10] Kim S Cameron and Robert E Quinn, Diagnosing and Changing Organizational Culture: Based on the Competing Values Framework, Revised ed.: Jossey-Bass, 2011.

[11] P. T Van den Berg and C. P. Wilderom, "Defining, measuring, and comparing organisational cultures," Applied Psychology, vol. 53, no. 4, pp. 570-582, 2004.

[12] P. G Huber, "Issues in the design of group decision support sytems," MIS Quartely, pp. 195 - 204, 1984.

[13] Nunamaker et al., "Electronic Meeting Systems," Communications of the ACM, vol. 34, no. 7, July 1991.

[14] R Cole, S Purao, M Rossi, and M. Sein, "Being proactive: where action research meets design research," in ICIS 2005 Proceedings, 2005.

[15] Juhani Iivari and J Venable, "Action research and design science research-seemingly similar but decisively dissimilar," European Conference on Information Systems, vol. 17, pp. 1-13, dec 2009.

[16] P. G Keen, Decision support systems: a research perspective. Decision Support Systems: Issues and Challenges. New York: Pergamon Press, 1980.

[17] M Beaudouin-Lafon and W. E Mackay, "prototyping tools and techniques," in Human Computer InteractionDevelopment Process, Andrew Sears and Julie A. Jacko, Eds.: CRC Press , 2003, ch. 52, pp. 122-142.

[18] W. J Orlikowski and C. S. Iacono, "Research commentary: Desperately seeking the "IT" in IT research-A call to theorizing the IT artifact.," Information systems research, vol. 12, pp. 121-134, 2001.

[19] J. Z Gottlieb and I Levin, Realigning organization culture for optimal performance: Six principles \& eight practices, 2009. 